\title{
Trafik Kazalarında Çocukluk Çağında Mortalite ve Morbiditenin Değerlendirilmesi
}

\author{
Mortality And Morbidity in Children As Traffic Accident Victims \\ Didem BASKIN EMBLETON', İrem ERTORAN², Nur ÖNEN² ${ }^{2}$ Abdurrahman ÖZKAN², Hakan MERSIN², \\ Murat Cemil TEKELi ${ }^{2}$
}

${ }^{1}$ Afyon Kocatepe Üniversitesi, Tıp Fakültesi, Çocuk Cerrahisi AD, Afyonkarahisar

${ }^{2}$ Afyon Kocatepe Üniversitesi, Tıp Fakültesi Öğrencisi, Afyonkarahisar

\begin{abstract}
öz
Amaç: Trafik kazaları önemli bir ölüm ve sakatlık nedeni olmaya devam etmektedirler. Çalışmada, trafik kazası sonucu hastaneye başvuran çocuklarda morbidite ve mortalite nedenleri araştırılarak bu nedenlere yönelik farkındalığın artırılması amaçlandı.

Gereç ve Yöntem: Acil servise 1 Kasım 2012-31 Ekim 2013 tarihleri arasında trafik kazası nedeniyle getirilen ve kazanın üzerinden en az 1 yıl geçen 0-18 yaş arası çocuklar retrospektif olarak incelendi. Yaş, cinsiyet, kazanın oluş şekli, mevsimsel dağılım, yaralanma bölgeleri, hastanede yatış gereksinimi, yatış süreleri, kalıcı sakatlıklar, ölümler ve nedenleri kaydedildi.
\end{abstract}

Bulgular: Acil servise trafik kazası nedeniyle 263 pediatrik olgu getirildi. Olguların \%60.1'i erkekti, yaş ortalaması 11.2 yıldı. Okul çağı yaş grubunun oranı \%78.3'tü. Araç içi trafik kazaları (AiTK) \%54 ile en büyük grubu, üstü açık araç yaralanmaları ise \%16.7 ile en küçük grubu oluşturdu. Kazalar en fazla yaz mevsiminde görüldü (\%45.6). Hastaların \%47.1'inde yatış gerektiren bulgu yoktu, \%39.9 tek bölge travması, \%12.9 çoklu travma saptandı. Hastalar ortalama 6.9 gün hastanede yattılar, \%3.8'i hayatını kaybetti, \%1.9'unda kalıcı sakatlık saptandı. Araç dışı trafik kazalarında (ADTK) mortalite ve morbidite daha yüksekti. En fazla mortalite ve morbidite, santral sinir sistemi yaralanmalarında görüldü.

Sonuç: Erkek çocuklar daha fazla trafik kazasına maruz kalmaktadırlar. ADTK'larında mortalite ve morbidite daha yüksektir ve önlenebilmesi için çalışmalar yapılmalıdır.

Anahtar Kelimeler: Trafik kazası, Çocuk, Mortalite, Morbidite

\begin{abstract}
Background: Traffic accidents are still important causes of disabilities and death. In this study, we aimed to examine the causes of morbidity and mortality in children that are victims of a traffic accident and increase the awareness to such causes.
\end{abstract}

Methods: Children aged 0-18 years that were brought to the emergency room because of a traffic accident between October 2012 and November 2013 were included in the study to make sure that at least one year has passed after the accident. Age, gender, type of the accident, season, injury sites, hospitalization requirement, hospitalization time, disabilities, death and causes of death were noted.

Results: Two hundred and sixty three children were brought to the emergency room as victims of a traffic accident. Of these, $60.1 \%$ were boys and the mean age was 11.2 years. School age group consisted $78.3 \%$ of the cases. While vehicle crashes made the largest group (54\%), open vehicles made the smallest (16.7\%). Most of the accidents occurred in summer (45.6). There was no serious injury needing hospitalization in $47,1 \%$ of the patients, $39.9 \%$ suffered single site and $12.9 \%$ multiple site injuries. Mean hospitalization time was 6.9 days, 3.8\% of the patients died and $1.9 \%$ suffered permanent disabilities. Mortality and morbidity were higher in pedestrian injuries. Most of the mortality and morbidity resulted from central nervous system injuries.

Conclusion: Boys are more prone to traffic accidents. Pedestrian accidents have higher mortality and morbidity, and more work needs to be done to prevent them.

Key words: Traffic accident, Child, Mortality, Morbidity 


\section{GíRiş}

Trafik; yayaların, hayvanların ve araçların karayolu üzerindeki hal ve hareketleridir. Trafik kazası ise karayolunda hareket halinde olan bir veya birden fazla aracın karıştığı ölüm, yaralanma ve zararla sonuçlanmış olaylardır (1). Günümüzde trafik kazaları, savaşlar ve depremlerdeki kadar insanın ölüm ve yaralanmasına neden olmakta, aynı zamanda bu olaylar nedeniyle doğan maddi zararlar da yıldan yıla artmaktadır.

Karayolu trafik kazaları büyük bir halk sağlığı ve gelişim sorunudur. Karayolu trafik kazaları tek başına tüm dünyada meydana gelen ölümlerin \%21'ine yol açmakta ve ölüm nedenleri arasında 11. sırada gelmektedir. Karayolu trafik kazaları ortalama olarak her yıl 1.2 milyon kişinin ya da her gün 3242 kişinin ölümüne yol açmaktadır. Ayrıca her yıl 20 - 50 milyon kişinin yaralanmasına ya da sakat kalmasına neden olmaktadır (2).

Ülkemizde de trafik kazalarının sıklığı, halen önemli bir sorun olmaya devam etmektedir (3). Ülkemiz karayolu ağında 2013 yılında toplam 1 207354 adet trafik kazası meydana gelmiştir. Bu kazaların 1046048 adedi maddi hasarlı 161306 adedi ise ölümlü yaralanmalı trafik kazasıdır (4). Bu çalışmada; trafik kazası sonrası hastaneye başvuran çocuklarda, morbidite ve mortalitenin diğer faktörlerle ilişkisi araştırılarak, trafik kazalarıyla ilgili farkındalığın artmasına yardımcı olmak amaçlanmıştır.

\section{GEREÇ ve YÖNTEM}

1 Kasım 2012 - 31 Ekim 2013 tarihleri arasında bir üniversite hastanesine trafik kazası nedeniyle başvuran 0-18 yaş grubundaki hastaların dosyaları geriye dönük olarak incelendi. Kalıcı sekelleri veya geç mortaliteyi daha iyi saptayabilmek için kazanın üzerinden en az 1 yıl geçmesine dikkat edildi.

Çalışmaya alınan vakaların yaş grupları, cinsiyeti, kazanın oluş şekli, yaralanma bölgeleri, kalıcı sakatlık durumu, mevsimsel dağılım, hastanede yatıp yatmadığı, yattıysa ne kadar süre yattığı kaydedildi.

Yaralanmalar bölgelerine göre baş-boyun, ekstremite, gövde (toraks/ pelvis/karın), multiple (birden fazla bölge) olarak belirlendi.
Kaza tipleri araç içi trafik kazası (AITK), araç dışı trafik kazası (ADTK) ve bisiklet/motorsiklet/tarım araçlarına bağlı kazalar az sayıda olduğundan bir araya getirilerek üstü açık araç kazası (ÜAAK) olarak gruplandırıldı.

Yaş grupları okul öncesi $(<7)$ ve okul çağı $(7 \geq)$ olarak sınıflandırıldı.

Çalışma sonunda elde edilen veriler SPSS (Statistical Package for Social Science) 20.0 istatistik programına göre değerlendirildi. Verilerin istatistiksel analizleri Chi-Kare testi ile hesaplandı, elde edilen bulgulardan $\mathrm{p}<0.05$ olan durumlar anlamlı kabul edildi.

Etik kurul onayı: Çalışma, Yerel Klinik Araştırmalar Kurulu'nun 08.01.2015 tarih ve 2015/01-18 sayılı kararıyla onaylanmıştır.

\section{BULGULAR}

Araştırma kapsamında üniversite hastanesinin acil servisine 1 Kasım 2012- 31 Ekim 2013 tarihleri arasında trafik kazası nedeniyle başvuran 263 pediatrik olgu retrospektif olarak incelendi. Bu olguların \%60.1'i ( $n=158)$ erkek, \%39.9'u ( $n=105)$ kız olup, yaş ortalaması 11.2, okul çağı yaş grubu \%78.3'ü $(n=206)$ iken okul öncesi yaş grubu \%21.7 ( $n=57)$ idi (Tablo 1).

Tablo 1: Kaza tiplerine göre verilerin gruplandırılmas

\begin{tabular}{|c|c|c|c|c|c|c|c|c|}
\hline & \multicolumn{2}{|c|}{ AITK } & \multicolumn{2}{|c|}{ ADTK } & \multicolumn{2}{|c|}{ ÜSTÜ AÇIK ARAÇ } & \multirow{2}{*}{$\begin{array}{c}\text { TOPLAM } \\
\%\end{array}$} & \multirow[t]{2}{*}{$P$} \\
\hline & $\mathrm{N}$ & $\%$ & $\mathrm{~N}$ & $\%$ & $\mathrm{~N}$ & $\%$ & & \\
\hline \multicolumn{9}{|l|}{ CINSIYET } \\
\hline KIZ & 72 & 27.4 & 25 & 9.5 & 8 & 3 & 39.9 & \\
\hline ERKEK & 70 & 26.6 & 52 & 19.8 & 36 & 13.7 & 60.1 & $P=0.000$ \\
\hline \multicolumn{9}{|l|}{ MEVSIM } \\
\hline KIŞ & 11 & 4.2 & 8 & 3 & 0 & 0 & 7.2 & \\
\hline ILKBAHAR & 23 & 8.7 & 21 & 8 & 14 & 5.3 & 22.1 & \\
\hline YAZ & 67 & 25.5 & 29 & 11 & 24 & 9.1 & 45.6 & $P=0.26$ \\
\hline SONBAHAR & 41 & 15.6 & 19 & 7.2 & 6 & 2.3 & 25.1 & \\
\hline \multicolumn{9}{|l|}{ YAŞ GRUPLARI } \\
\hline OKUL ÖNCESI & 34 & 12.9 & 16 & 6.1 & 7 & 2.7 & 21.7 & \\
\hline OKUL ÇAĞI & 108 & 41.1 & 61 & 23.2 & 37 & 14.1 & 78.3 & $P=0.515$ \\
\hline \multicolumn{9}{|c|}{ YARALANMA BÖLGESI } \\
\hline BAŞ-BOYUN & 26 & 9.9 & 18 & 6.8 & 9 & 3.4 & 20.2 & \\
\hline EKSTREMITE & 17 & 6.5 & 17 & 6.5 & 5 & 1.9 & 14.8 & \\
\hline GÖVDE & 5 & 1.9 & 4 & 1.5 & 4 & 1.5 & 4.9 & $P=0.000$ \\
\hline MULTIPLE & 8 & 3 & 18 & 6.8 & 8 & 3 & 12.9 & \\
\hline YOK & 86 & 32.7 & 20 & 7.6 & 18 & 6.8 & 47.1 & \\
\hline
\end{tabular}


Trafik kazaları tiplerine göre AiTK \%54 ( $n=142)$ ile en büyük grup iken, üstü açık araç kazaları (ÜAAK) da \%16.7 ( $n=44)$ ile en küçük grubu oluşturdu.

En fazla başvuru \%45.6 $(n=120)$ ile yaz mevsiminde, en az başvuru \%7.2 ( $n=19)$ ile kış mevsiminde idi. AiTK'ları tüm mevsimlerde en yüksek oranda görülen kaza tipiydi (Grafik 1).

Grafik 1: Mevsimlere göre kaza tipleri

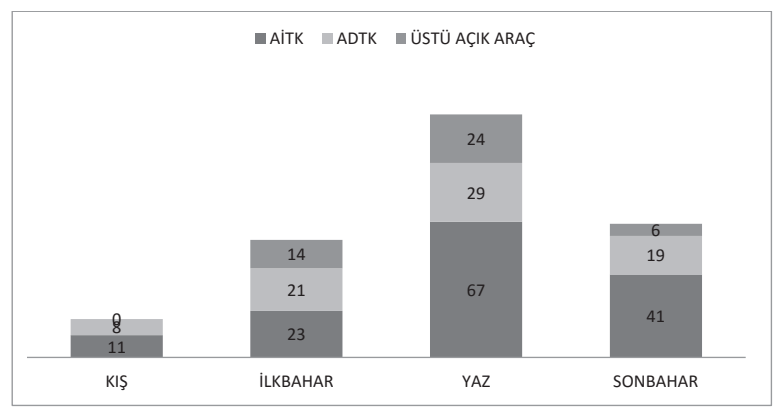

Hastaların \%47.1'inde ( $n=124)$ ciddi bir yaralanma bulgusu saptanmadı, \%39.9'unda $(n=105)$ tek bölge travması, \%12.9'unda( $n=34)$ çoklu travma saptandı. Tek bölge travmalarının $\% 50.5$ i $(n=53)$ baş-boyun bölgesinde idi (Grafik 2).

Grafik 2: Kaza tiplerine göre travma bölgeleri

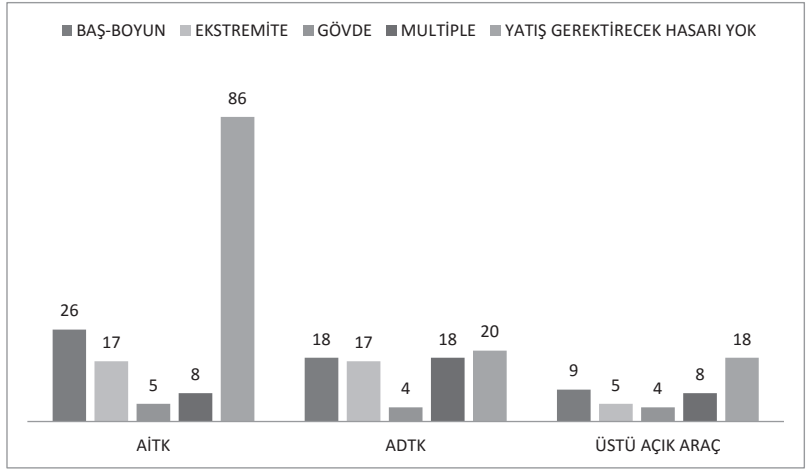

Yatış endikasyonu koyulan hastalar \%32.3 ( $n=85$ ) oranında iken, bu olgularda hastanede yatış süresi ortalama 6.9 (maksimum=69, minimum=1) gün idi.

Yatış sürecinde hastaların \%3.8'inin $(n=10)$ hayatını kaybettiği, \%1.9'unda $(n=5)$ kalıcı sakatlık meydana geldiği tespit edildi (Grafik 3,4) (Tablo 2). Santral sinir sistemi hasarlarının ölümlerin 8'inden ve kalıcı sakatlıkların 2'sinden sorumlu olduğu görüldü.

\section{İstatistiksel değerlendirme:}

Kaza tiplerine bakıldığında, mortalite ve morbidite araç dışı trafik kazalarında anlamlı olarak daha yüksekti $(p=0.00)$ : AiTK'da morbidite \%17.6, mortalite \%2.1 iken, ADTK'larında morbidite \%44.2, mortalite \%7.8 olarak bulundu (Tablo 2).

Tablo 2: Morbiditeye göre verilerin değerlendirilmesi

\begin{tabular}{|c|c|c|c|c|c|c|c|c|}
\hline & \multicolumn{2}{|c|}{ MORBIDITE YOK } & \multicolumn{2}{|c|}{ MORBIDITE VAR } & \multicolumn{2}{|c|}{ ÖLÜM } & \multirow{2}{*}{$\begin{array}{c}\text { TOPLAM } \\
\%\end{array}$} & \multirow{2}{*}{ P } \\
\hline & $\mathrm{N}$ & $\%$ & $\mathrm{~N}$ & $\%$ & $\mathrm{~N}$ & $\%$ & & \\
\hline \multicolumn{9}{|l|}{ KAZA TiPLERI } \\
\hline AITK & 114 & 43.3 & 25 & 9.5 & 3 & 1.1 & 54 & $P=0.000$ \\
\hline ADTK & 37 & 14.1 & 34 & 12.9 & 6 & 2.3 & 29.3 & \\
\hline ÜSTÜ AÇIK ARAÇ & 23 & 8.7 & 20 & 7.6 & 1 & 0.4 & 16.7 & \\
\hline \multicolumn{9}{|l|}{ MEVSiM } \\
\hline KIŞ & 12 & 4.6 & 6 & 2.3 & 1 & 0.4 & 7.2 & \\
\hline ILKBAHAR & 36 & 13.7 & 20 & 7.6 & 2 & 0.8 & 22.1 & $P=0.887$ \\
\hline YAZ & 80 & 30.4 & 37 & 14.1 & 3 & 1.1 & 45.6 & \\
\hline SONBAHAR & 46 & 17.5 & 16 & 6.1 & 4 & 1.5 & 25.1 & \\
\hline \multicolumn{9}{|l|}{ YAŞ GRUPLARI } \\
\hline OKUL ÖNCESI & 37 & \begin{tabular}{|l|}
14.1 \\
\end{tabular} & 16 & 6.1 & 4 & 1.5 & 21.7 & $P=0.478$ \\
\hline OKUL ÇAĞI & 137 & 52.1 & 63 & 24 & 6 & 2.3 & 78.3 & \\
\hline \multicolumn{9}{|l|}{ CINSIYET } \\
\hline KIZ & 75 & 28.5 & 29 & 11 & 1 & 0.4 & 39.9 & $P=0.180$ \\
\hline ERKEK & 99 & 37.6 & 50 & 19 & 9 & 3.4 & 60.1 & \\
\hline
\end{tabular}

Grafik 3: Mortalite Nedenleri
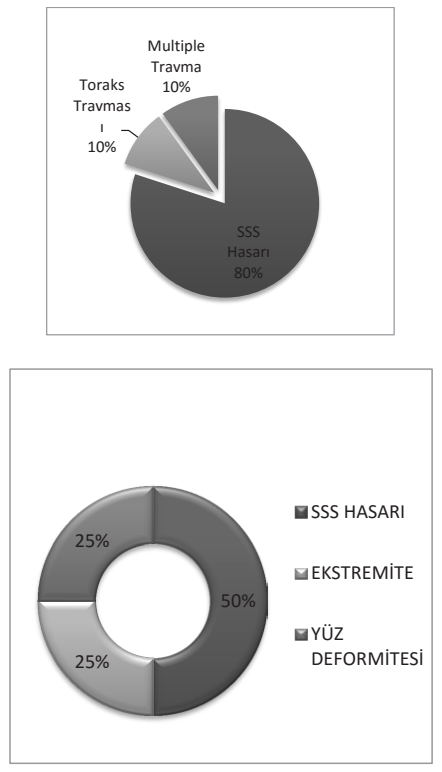

Grafik 4. Kalıcı sakatlık nedenleri

Okul öncesi çocuklarla okul çağı çocuklar mortalite ve morbidite açısından karşılaştırıldığın$d a$, iki grup arasında fark önemsizdi ( $p=0.352)$. Cinsiyetle mortalite ve morbidite karşılaştırıldığında, kızlarla erkekler arasında fark bulunma- 
dı $(p=0.090)$. Mevsimlerle mortalite-morbidite oranları karşılaştırıldığında önemli bir fark bulunmadı $(p=0.808)$ (Tablo 2).

Kaza tipleri ile okul öncesi ve okul çağı çocuklar karşılaştırıldığında, okula gidip gitmemenin kaza tipleri ile bir ilgisi olmadığı görüldü $(p=0.515)$ (Tablo 2). Çocukların \%84.1'ini okul çağı çocuklar oluşturdu.

Ancak mevsimlerle kaza çeşitleri arasında fark vardı ( $p=0.026)$. Kışın üstü açık araç kazası görülmezken, ilkbaharda kaza tipleri birbirine yakın oranlar gösterdi. Yine de oran, AiTK'larında tüm mevsimlerde yüksektir (Tablo 1) (Grafik 1). Yaralanma olup olmadığıyla kaza tipleri karşılaştırıldığında fark önemliydi $(p=0.00)$. Yaralanma oranlarına bakıldığında AiTK'larıın \%39.4'ünde yaralanma varken, bu oran ADTK'larında \%74'e çıkmaktadır. ÜAAK'larında ise yaralanma oranı \%59.1'dir. Yaralanma bölgelerine bakıldığında, en fazla yaralanma baş-boyun bölgesinde görülürken (\%20.2), bu oran kaza tipleri karşılaştırıldığında \%49.1 ile AiTK'larında en yüksekti (Tablo 1) (Grafik 2).

Kaza cinsi ile cinsiyet karşılaştırıldığında, yine aradaki fark önemliydi $(p=0.00)$. Erkek çocuklar kız çocuklarından belirgin olarak daha fazla ADTK ve ÜAAK'sına karıştılar (Tablo 2).

\section{TARTIŞMA}

Trafik kazaları, çocukluk çağının en sık ölüm nedenidir ve travmaya bağlı yatış nedenleri arasında ilk sırada yer almaktadır (5). Türkiye İstatistik Kurumu'nun yayınladığı 2013 karayolu istatistiklerine ve çocuk istatistiklerine bakıldığında, kazaya karışanların sürücü, yolcu ve yaya olarak gruplandırıldığı görülmektedir. Ayrıca kazalar motosiklet, otomobil, minibüs, kamyonet, kamyon, çekici, otobüs ve traktör kazaları olarak gruplandırılmış, bisiklet kazalarına yer verilmemiştir [4]. Çalışmamızda bu gruplanma, pratikte kullandığımız şekliyle araç içi trafik kazası, araç dışı trafik kazası ve özelikli bir grup olması nedeniyle de motorsiklet, bisiklet ve tarım araçlarını içeren üstü açık araç kazası olarak yapılmıştır. En büyük grubu araç içi trafik kazaları oluşturmuştur.
Yaralanmaların sonuçları ile ilgili ise ek bilgi yoktur. Buna göre, 2013 yılında trafik kazalarında 0-17 yaş aralığında 413 çocuk (\%11.2) ölmüş, 48307 çocuk (\%17.6) yaralanmıştır (6). Yine çoğunluk erkek çocuklardadır. Çocuk ölümlerinin 202'si (\%48.8) 0-9 yaş grubundadır. Yaya ölümleri \%35.8 oranında görülmüştür. Çalışmamı da bunu desteklemektedir. TÜiK istatistiklerinde yaralananların kaçının daha sonra öldüğü, kaçının ise sakat kaldığı belli değildir. Ayrıca, il istatistiklerine bakıldığında, çalışmanın yapıldığı il olan Afyonkarahisar'da 2013 yılı 10000 araç başına trafik kaza sayısı, 100 olarak gerçekleşmiştir. Bu değer, 90 olan Türkiye değerinin üstündedir (7).

Küçüker ve arkadaşlarının yaptığı çalışmada (8) yaralanmaların \%41.8'i AiTK, \%41.2'si ADTK'na bağlı iken; bu çalışmada ise morbiditenin 43'ü, mortalitenin \%60'ı ADTK'na bağlıdır. Ayrıca AiTK'na maruz kalanların, \%49.3'ü; ADTK'na maruz kalanların \%67.5'i; ÜAAK'na maruz kalanların \%81.8'i erkek idi. Seriken ve arkadaşları (9) da beş yıllık çalışmalarında benzer bir sonuç elde etmişlerdir. Çalışmamızda trafik kazalarına maruz kalan çocukların $\% 60.1$ 'inin erkek olması literatürle ve Türkiye istatistikleriyle uygunluk göstermiştir. Erkek çocuklar kız çocuklarına oranla daha fazla ev dışında zaman geçirmektedir. Çocuğun bulunduğu sosyoekonomik ortam da kazaya uğrama olasılığını arttıran etkenlerden bir diğeridir. Sosyoekonomik ortamı iyi olmayan çevrede yetişen çocuklar, daha çok kazaya maruz kalmakta olup, bu durum çevre koşullarına (kaldırım düzenlemesi, trafik ışıkları, yol kalitesi, sürücülerin kültürel düzeyi vb.), ev dışında zaman geçirilen oyun parkı gibi güvenli mekanların oluşturulmaması ve ebeveynlerin gözetimlerinin daha az olmasına dayanır $(9,10)$. Kazalar değerlendirilirken bu verilerin de değerlendirilmesi gerekir. Tüik verilerinde trafik lambası, trafik işaret levhası, trafik görevlisi ya da banket olmayan yollarda daha yüksek oranda kaza görülmektedir. Çocuklarla ilgili ayrıca bir veri görülememiştir.

Kaza tiplerinin ve okul öncesi/okul çağı yaş grubu çocukların istatistiki olarak karşılaştırılmasında anlamlı bir farka rastlanmamıştır. Bu sonuç, 
eğitimin davranışlar üzerinde etkisi olacak düzeyde verilmediği düşüncesini doğurmuştur.

Toro ve arkadaşları (11) ile Varol ve arkadaşlarının (12) yapmış oldukları çalışmalarda trafik kazası nedeniyle ölümlerin en çok kafa travması nedeniyle olduğu bildirilmektedir. ÇaIışmamızda da olguların \%47.1'inde ciddi bir patoloji bulgusu gözlenmezken, \%20.2'sinde baş-boyun, \%14.8'inde ekstremite, \%12.9unda multiple travma, ve \%4.9'unda gövde travması bulunmuştur. Yaralanan hastaların çoğunun baş-boyun travması geçirmiş olması, diğer çaIışmaları destekler niteliktedir. Kalıcı sakatlık ve ölümler de en fazla santral sinir sistemi hasarlarına bağlı olarak ortaya çıkmıştır.

Ülkemizde gerçekleşen trafik kazaları en fazla yaz, en az ise kış mevsiminde görülmüştür [4]. Yapılan bu çalışmada diğer çalışmalara uygun olarak, kazaların \%45.6'sının yaz mevsiminde, \%7.2'sinin kış mevsiminde gerçekleştiği saptandı. Bu sonuca bakılarak yaz aylarında trafik ile ilgili ekstra önlemler alınması gerekliliği olduğu düşünülmüştür.

Sonuç olarak, ADTK'larının, oransal olarak AiTK'larından daha az sayıda olmasına rağmen, pediatrik yaş grubu içinde diğer kazalara göre daha sık mortalite ve morbiditeye neden olduğu, en çok da santral sinir sistemi hasarı oluşturduğu saptanmıştır. AiTK'larında emniyet kemeri bağlama, çocuk koltuğu gibi önlemler santral sinir sistemi hasarı olasılığını azaltsa da, ADTK'larında bu şans yoktur. Ayrıca incelenen trafik kazası tiplerine göre; okul öncesi ve okul çağı çocuklarında anlamlı bir fark bulunmamıştır, eğitim kaza oranlarını etkilememektedir. Erkek çocuk olmak ise kazaya davetiye çıkarmaktadır. Türkiye İstatistik Kurumu'nun yol durumu istatistiklerinde verilen bilgilerle birleştirildiğinde bu sonuçlar, trafik kuralları konusunda çocuklara, özellikle de erkek çocuklara verilen eğitimin yeterliliği ve yaya koşulları hakkında soruları akla getirmektedir. Çocuklarla ilgili veriler nedene yönelik olarak daha fazla detaylandırılarak kazalardaki ölüm ve yaralanmaların azaltılmasına çalışılmalıdır.

\section{KAYNAKLAR}

1. Polat O. Adli travmatolojide trafik kazalarına bakış. Adli Tıp Bülteni; 1996;1:18-25

2. Main messages from the report, in World Report on Road Traffic Injury Prevention, Ed: Peden M, Scurfield R, Sleet D, Mohan D,. Hyder AA, Jarawan E, Mathers C, World Health Organization, Geneva, s:157, 2004

3. Göksü E, Çete Y, Hüseyin Kanalıcı H, Kılıçarslan İ. Trafik kazası nedeniyle başvuran hastaların demografik, klinik özellikleri ve kan etil alkol düzeyi ile ilişkisi. Türkiye Acil Tıp Dergisi, 2008;8(1):26-31

4. Karayolu Trafik Kaza İstatistikleri, 2013. Emniyet Genel Müdürlüğü ve Türkiye İstatistik Kurumu, Türkiye İstatistik Kurumu Matbaası, Ankara, 2014

5. Sala D, Fernandez E, Morant A, Gasco J, Barrios C. Epidemiologic aspects of pediatric multiple trauma in a Spanish urban population. J Pediatr Surg, 2000;35:1478-81

6. İstatistiklerle Çocuk: 2014. Türkiye İstatistik Kurumu, Türkiye İstatistik Kurumu Matbaası, Ankara, 2015

7. Seçilmiş Göstergelerle, Afyonkarahisar, 2013, Türkiye İstatistik Kurumu, Türkiye İstatistik Kurumu Matbaası, Ankara, Grafik 1.27, s:34, 2014

8. Küçüker $H$, Aksu A. Evaluation of traffic accident cases admitted to the emergency department of the Firat University Hospital in 1997-2001 [article in Turkish] Tr J Emerg Med, 2003;3(2):11-5

9. Serinken $M$, Özen M. Pediyatrik yaş grubunda trafik kazası sonucu oluşan yaralanmalar ve özellikleri. Ulus Travma Acil Cerrahi Derg, 2011;17 (3):243-247

10. Bertan M, Güler Ç. Halk Sağlığı Temel Bilgiler, Ankara, Güneş Kitabevi, 1995

11. Toro $K$, Hubay $M$, Sotonyi $P$, Keller E. Fatal traffic injuries among pedestrians, bicyclists and motor vehicle occupants. Forensic Sci Int; 2005;151(2-3):151-6

12. Varol O, Eren Ş, Oğuztürk H, Korkmaz İ, Beydilli í. Acil servise trafik kazası sonucu başvuran hastaların incelenmesi. Cumhuriyet Üniversitesi Tıp Fakültesi Dergisi, 2006;28(2):55-60 